\title{
Self-replenishing ability of cross-linked low surface energy polymer films investigated by a complementary experimental- simulation approach
}

\author{
Citation for published version (APA): \\ Esteves, A. C. C., Lyakhova, K., Riel, van, J. M., Ven, van der, L. G. J., Benthem, van, R. A. T. M., \& With, de, \\ G. (2014). Self-replenishing ability of cross-linked low surface energy polymer films investigated by a \\ complementary experimental-simulation approach. Journal of Chemical Physics, 140, 1-9. [124902]. \\ https://doi.org/10.1063/1.4868989
}

DOI:

$10.1063 / 1.4868989$

Document status and date:

Published: 01/01/2014

\section{Document Version:}

Publisher's PDF, also known as Version of Record (includes final page, issue and volume numbers)

\section{Please check the document version of this publication:}

- A submitted manuscript is the version of the article upon submission and before peer-review. There can be important differences between the submitted version and the official published version of record. People interested in the research are advised to contact the author for the final version of the publication, or visit the DOI to the publisher's website.

- The final author version and the galley proof are versions of the publication after peer review.

- The final published version features the final layout of the paper including the volume, issue and page numbers.

Link to publication

\footnotetext{
General rights

- You may freely distribute the URL identifying the publication in the public portal. follow below link for the End User Agreement:

www.tue.nl/taverne

\section{Take down policy}

If you believe that this document breaches copyright please contact us at:

openaccess@tue.nl

providing details and we will investigate your claim.
}

Copyright and moral rights for the publications made accessible in the public portal are retained by the authors and/or other copyright owners and it is a condition of accessing publications that users recognise and abide by the legal requirements associated with these rights.

- Users may download and print one copy of any publication from the public portal for the purpose of private study or research.

- You may not further distribute the material or use it for any profit-making activity or commercial gain

If the publication is distributed under the terms of Article $25 \mathrm{fa}$ of the Dutch Copyright Act, indicated by the "Taverne" license above, please 


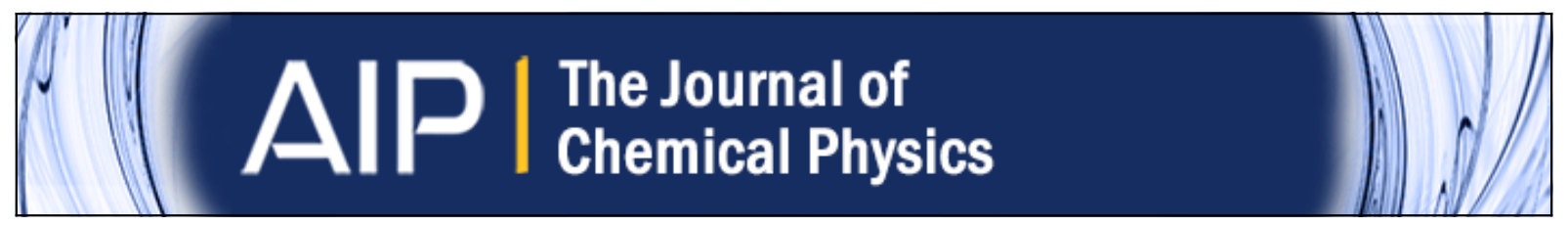

Self-replenishing ability of cross-linked low surface energy polymer films investigated by a complementary experimental-simulation approach

A. C. C. Esteves, K. Lyakhova, J. M. van Riel, L. G. J. van der Ven, R. A. T. M. van Benthem, and G. de With

Citation: The Journal of Chemical Physics 140, 124902 (2014); doi: 10.1063/1.4868989

View online: http://dx.doi.org/10.1063/1.4868989

View Table of Contents: http://scitation.aip.org/content/aip/journal/jcp/140/12?ver=pdfcov

Published by the AIP Publishing

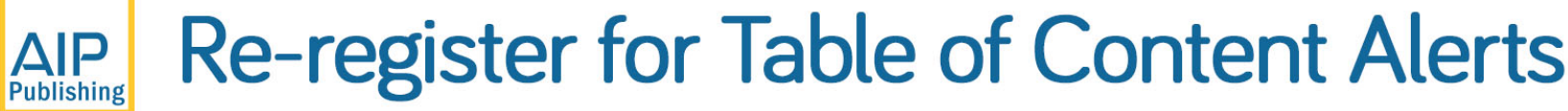

\section{Create a profile.}




\title{
Self-replenishing ability of cross-linked low surface energy polymer films investigated by a complementary experimental-simulation approach
}

\author{
A. C. C. Esteves, ${ }^{1, \text { a) }}$ K. Lyakhova, ${ }^{1}$ J. M. van Riel, ${ }^{1}$ L. G. J. van der Ven, ${ }^{1,2}$ \\ R. A. T. M. van Benthem, ${ }^{1,3}$ and G. de With ${ }^{1, a)}$ \\ ${ }^{1}$ Laboratory of Materials and Interface Chemistry, Department of Chemical Engineering and Chemistry, \\ Eindhoven University of Technology, Eindhoven, The Netherlands \\ ${ }^{2}$ AkzoNobel, Automotive \& Aerospace Coatings, Sassenheim, The Netherlands \\ ${ }^{3}$ DSM Ahead, Geleen, The Netherlands
}

(Received 22 January 2014; accepted 7 March 2014; published online 24 March 2014)

\begin{abstract}
Nowadays, many self-healing strategies are available for recovering mechanical damage of bulk polymeric materials. The recovery of surface-dependent functionalities on polymer films is, however, equally important and has been less investigated. In this work we study the ability of low surface energy cross-linked poly(ester urethane) networks containing perfluorinated dangling chains to self-replenish their surface, after being submitted to repeated surface damage. For this purpose we used a combined experimental-simulation approach. Experimentally, the cross-linked films were intentionally damaged by cryo-microtoming to remove top layers and create new surfaces which were characterized by water Contact Angle measurements and X-Ray Photoelectron Spectroscopy. The same systems were simultaneously represented by a Dissipative Particles Dynamics simulation method, where the damage was modeled by removing the top film layers in the simulation box and replacing it by new "air" beads. The influence of different experimental parameters, such as the concentration of the low surface energy component and the molecular mobility span of the dangling chains, on the surface recovery is discussed. The combined approach reveals important details of the self-replenishing ability of damaged polymer films such as the occurrence of multiplehealing events, the self-replenishing efficiency, and the minimum "healing agent" concentration for a maximum recovery. (O) 2014 AIP Publishing LLC. [http://dx.doi.org/10.1063/1.4868989]
\end{abstract}

\section{INTRODUCTION}

During the last decade functional materials with easy-toclean/self-cleaning, ${ }^{1}$ antimicrobial, ${ }^{2}$ or anti-fouling ${ }^{3}$ properties have been intensively investigated driven by an increasing industrial demand and a growing academic interest. While the challenge to make such functional surfaces produced a considerable number of new materials and methods, it is important now to move further and make them in a sustainable way, i.e., robust, durable, easy to manufacture and scale-up.

These advanced surface functionalities are mainly determined by the surface chemical composition and, in some cases, surface topography as well. The surface is, however, simultaneously the "beauty and the beast" of materials and devices. Being the first contact border with different environments, chemicals, and users, it is naturally prone to damage which very often extends to the bulk or underlying materials. Hence introducing a surface-self-repairing mechanism into functional materials is one way to ensure their high level of performance and an extended service life-time with reduced maintenance and repair costs. ${ }^{4,5}$ In fact, selfhealing is currently one of the most active topics in materials science. $^{6-8}$ For polymers ${ }^{9-11}$ and polymer coatings ${ }^{12-15}$ several approaches have been reported to restore the integrity of the material, either by refilling the damaged areas, e.g.,

\footnotetext{
a)Electronic addresses: a.c.c.esteves@tue.nl and g.dewith@tue.nl
}

via encapsulated reactive components (autonomous healing) or by reestablishing chemical bonds through reversible reactions triggered by external stimuli such as temperature, light or a $\mathrm{pH}$ switch (triggered healing). These approaches can use intrinsic healing concepts, ${ }^{16-19}$ in which the healing agent is inherent to the material (i.e., is a part of the network or formulation) or extrinsic healing, where external components are added, such as filled capsules ${ }^{20-23}$ or microvascular networks. ${ }^{24,25}$ The intrinsic healing concept may allow multiple healing events but requires a certain mobility of the system (or at least part of it). Moreover, in the majority of the cases an external trigger is needed to start the repairing mechanism. On the other hand, the external healing concept allows a localized response but is rather limited for multiple healing events and, for each system, specific healing agents compatible with the other components need to be found.

Recently, we reported an intrinsic and autonomous surface-repairing concept based on self-replenishing of surfaces $^{26}$ through the surface self-segregation of functional groups connected to the polymer network towards the damage loci, using energy differences as driving force. The proofof-principle was reported for cross-linked polymer films containing perfluoroalkyl-polymeric dangling ends (as low surface energy end-groups), which self-orient towards the new air-polymer interfaces created upon damage. The surface selfreplenishing was proven to occur at room temperature for soft cross-linked poly(ester urethane) films $\left(T_{\mathrm{g}} \sim-40^{\circ} \mathrm{C}\right)$ as well 
as, at somewhat more elevated temperatures ${ }^{26}$ for films with higher $T_{\mathrm{g}}$ (temperature triggering).

In order to control and optimize the self-replenishing of such hydrophobic systems, it is of primordial importance to understand how the systems are firstly formed, how the surface segregation occurs and which parameters can be tuned to control it. In a previous work $^{27}$ we reported a combined experimental-simulation study to investigate the surface-segregation occurring during the film formation (cross-linking) of these model low surface energy systems. A number of parameters were varied systematically in analogous experimental and simulation set-ups. We showed that the combination of a significant fluorine concentration in the formulation and a polymeric spacer with a specific length allows reaching an optimum hydrophobicity upon film formation. ${ }^{27}$ Using the dual approach we also gained additional insight into the dynamics and network structure of the films, such as the existence of a depletion zone beneath the top surface-segregated layer and the presence of "clusters" of the dangling chains in the bulk.

In the current paper, we report the self-healing response of these surface-segregated cross-linked films when submitted to consecutive damage. Following a similar experimentalsimulation approach, we studied the effect of several system parameters on the surface-recovery ability: (1) the concentration of the low surface energy component (fluorine wt.\%), (2) the molecular mobility span of the dangling chains, and (3) the polymer network segments length. The cross-linked films were characterized experimentally by water Contact Angle (CA) and X-Ray Photoelectron Spectroscopy (XPS) measurements and simultaneously represented by a coarse grained Dissipative Particle Dynamics (DPD) simulation method. The films were intentionally damaged: experimentally, using cryomicrotoming and via simulations, mimicking the damage by removing the top layers in the simulation box and replacing it by a new "air" layer. The surface healing of the polymer films is described in parallel from an experimental and simulation point of view.

\section{EXPERIMENTAL}

\section{A. Chemicals}

2-Ethyl-2-(hydroxymethyl)-1,3-propanediol

(TMP) (Merck, $\geq 99 \%$ ) and Fumaric acid (Fluka) were dried in a vacuum oven at $40^{\circ} \mathrm{C}$ for $3 \mathrm{~h}$ prior to use. $\varepsilon$-Caprolactone (CL) (Sigma-Aldrich, 99\%) was vacuum-distilled to remove traces of water. Perfluorooctyl ethanol $\left(\mathrm{F}_{17} \mathrm{C}_{8}-\mathrm{OH}\right)$ (Clariant $\mathrm{GmbH}$ ) was used as received. Solvents p.a. grade: thetrahydrofuran (THF), $n$-heptane, $N$-methyl pyrrolidone (NMP), and methanol were used as received without further purification.

\section{B. Experimental characterization}

${ }^{1} \mathrm{H}$ NMR spectra were recorded on a Varian 400 spectrometer at $25^{\circ} \mathrm{C}$, operating at $400 \mathrm{MHz} . \mathrm{CDCl}_{3}$ (with $0.01 \%$ wt TMS) was used as solvent. Matrix-assisted laser desorption/ionization time-of-flight mass spectrometry
(MALDI-ToF MS) measurements were performed on a Voyager-DE Pro instrument (Perspective Biosystems, Framingham, MA). The polymers were dissolved in THF and NaTFA or KTFA (sodium or potassium trifluoroacetate) were used as the ionizing agents.

The glass transition temperatures $\left(T_{\mathrm{g}}\right)$ were determined on a Q2000 TA differential scanning calorimeter (DSC) in a range from $-90^{\circ} \mathrm{C}$ to $+100^{\circ} \mathrm{C}$. A first heating and cooling scans were performed at $10^{\circ} \mathrm{C} / \mathrm{min}$ to eliminate the thermal history of the samples. The $T_{\mathrm{g}}$ of polymers and cross-linked films were determined at the half-way heat capacity of a second heating run at heating rate of $10^{\circ} \mathrm{C} / \mathrm{min}$.

Dynamic water CA measurements were performed on a Dataphyscis OCA 30 at room temperature, using de-ionized water as probe liquid. Water droplets were measured in advancing and receding mode and the reported results are the average of four drop measurements at different locations of the three replicas prepared for each film. The error bars provided in the graphs correspond to the sample standard deviation of three films measured.

$\mathrm{X}$-ray photoelectron spectroscopy measurements were carried out with a K-Alpha, ThermoScientific spectrometer using an aluminum anode ( $\mathrm{Al} \mathrm{K} \alpha=1486.3 \mathrm{eV}$ ) operating at $510 \mathrm{~W}$ with a background pressure of $\sim 2 \cdot 10^{-8} \mathrm{mbar}$. The spectra were recorded using the VGX900 data system collecting an average of 60 scans. All carbon C1s peaks corresponding to hydrocarbons were calibrated at a binding energy of $284.5 \mathrm{eV}$, to correct for the energy shift caused by charging. The spectra were acquired at take-off angle of $0^{\circ}$ relative to the surface normal, corresponding to a probe depth of $\sim 10$ $\mathrm{nm}$. The fluorine/carbon $(\mathrm{F} / \mathrm{C})$ atomic ratio was determined from curves fitted to the $\mathrm{C} 1 \mathrm{~s}$ spectra, according to different carbon environments $\left(\mathrm{C}-\mathrm{C}, \mathrm{C}-\mathrm{O}, \mathrm{C}=\mathrm{O}, \mathrm{C}-\mathrm{F}_{2}\right.$, and $\left.\mathrm{C}-\mathrm{F}_{3}\right)$. The areas were corrected for element sensitivity and the F/C ratio was estimated from the corresponding area ratios using

$$
\mathrm{F} / \mathrm{C}=\frac{[A(\mathrm{~F})]}{\left[A\left(\mathrm{CF}_{2}\right)+A\left(\mathrm{CF}_{3}\right)+A(\mathrm{C}=\mathrm{O})+A(\mathrm{C}\{-\mathrm{O})+A(\mathrm{C}-\mathrm{C})]\right.}
$$

where $A(\mathrm{~F})$ represents the total fluorine peak area and $A(\mathrm{CX})$ the peak areas of the various carbon peaks. Four different spots were measured on the three replicas prepared for each film. The error bars provided in the graphs correspond to the sample standard deviation of three films measured.

\section{Synthesis of 3-arm-poly(caprolactone) polyester precursors $\left(T M P-P C L_{x}\right)\left(1_{E X P}\right.$ in Scheme 1)}

The synthesis of the TMP- $\mathrm{PCL}_{\mathrm{x}}$ polyester precursors was made according to the method previously described. ${ }^{27,28}$ The precursors synthesized with different degree of polymerization (DP) and respective characterization are summarized in Table SM- $1 .{ }^{27}$

\section{Synthesis of fluorinated-poly(caprolactone) dangling chains $\left(F_{17} C_{8}-P C L_{y}\right)\left(2_{E X P}\right.$, Scheme 1)}

The synthesis of the $\mathrm{F}_{17} \mathrm{C}_{8}-\mathrm{PCL}_{\mathrm{y}}$ dangling chains was made according to the method previously described. ${ }^{27,28}$ All 


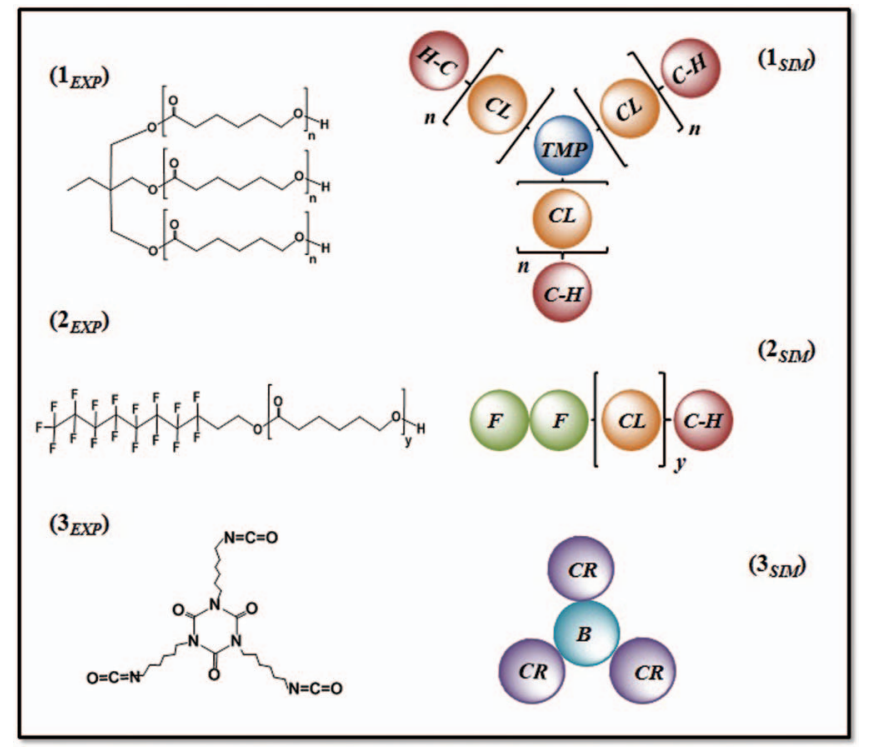

SCHEME 1. Low surface energy films components $(E X P=$ experimental and $S I M=$ simulation): (1) polyester precursor $\left(\mathrm{TMP}-\mathrm{PCL}_{x}, x=3 \times n\right.$, with $n$ number of caprolactone (CL) units per arm), (2) perfluorinated dangling chains $\left(\mathrm{F}_{17} \mathrm{C}_{8}-\mathrm{PCL}_{\mathrm{y}}, \mathrm{y}=\right.$ total number of $\mathrm{CL}$ units), and (3) tri-isocyanate cross-linker.

the dangling chains synthesized with different DP and the respective characterizations are described in Table SM-2. ${ }^{27}$

\section{Preparation of poly(ester urethane) cross-linked films with $\mathrm{F}_{17} \mathrm{C}_{8}-\mathrm{PCL} \mathrm{L}_{\mathrm{y}}$ dangling chains}

Poly(ester urethane) films were prepared from a mixture of the PCL precursors prepared (TMP-PCL ${ }_{\mathrm{x}}$ ) and a triisocyanate cross-linker, using NMP as solvent (45\% wt solid content). The molar ratio of $\mathrm{NCO} / \mathrm{OH}$ was kept at 1.1 to ensure the full conversion of $\mathrm{OH}$ groups. The mixture was applied by drop-casting on glass slides, which were previously cleaned by the following steps: rinsing with acetone, sonicated for $15 \mathrm{~min}$ in a sonication bath, cleaned with dust free tissue and finally flushed with air. The spread layers were then cured with the following fixed conditions: curing temperature of $125^{\circ} \mathrm{C}$ in a vacuum oven (pressure was about $20 \mathrm{mbar}$ ), curing time of $1 \mathrm{~h}, \mathrm{NMP}$ as solvent, solid content of $45 \% \mathrm{wt}$, $\mathrm{NCO} / \mathrm{OH}$ ratio of 1.1, and glass slides were used as substrates. Typically, the thickness of the cured films was from 300 to $500 \mu \mathrm{m}$. The polymeric films synthesized and the respective characterizations are described in Table I.

\section{Cryo-microtoming technique to mimic surface damage}

A microtome was used to cut horizontal slices through the depth of the films. To be able to cut slices plane parallel to the surface, a special home-made sample holder was mounted on a microtome. For the purposes of microtoming, substrates were round plates $(\emptyset=2 \mathrm{~cm})$ made of nickel, ground to be plan-parallel. To obtain films with acceptable roughness it was necessary to tune the temperature and the force/speed of cutting. Moreover, a "soft" knife (as utilized in soft tissue
TABLE I. Parameters and characterization of the cross-linked films studied. The numbers in italic and bold denote different sets of films.

\begin{tabular}{|c|c|c|c|c|}
\hline $\begin{array}{l}\text { TMP-PCL } \\
x=\end{array}$ & $\begin{array}{c}\mathrm{F}_{17} \mathrm{C}_{8}-\mathrm{PCL}_{\mathrm{y}} \\
\mathrm{y}=\end{array}$ & $\begin{array}{c}\% \mathrm{wt} \\
\text { danglingchains }^{\mathrm{a}}\end{array}$ & $\%$ wt $\mathrm{F}^{\mathrm{b}}$ & $\begin{array}{c}\mathrm{T}_{\mathrm{g}}\left({ }^{\circ} \mathrm{C}\right) \\
\text { (from DSC) }\end{array}$ \\
\hline 24 & 0.0 & 0.0 & 0.0 & -59 \\
\hline 24 & 16 & 4.6 & 0.5 & -46 \\
\hline 24 & 16 & 9.6 & 1.0 & -46 \\
\hline 24 & 16 & 15.0 & 1.5 & -46 \\
\hline 24 & 16 & 21.0 & 2.0 & -44 \\
\hline 24 & 16 & 34.0 & 3.0 & -47 \\
\hline 24 & 8 & 21.0 & 2.0 & -48 \\
\hline 24 & 12 & 21.0 & 2.0 & -47 \\
\hline 24 & 16 & 21.0 & 2.0 & -44 \\
\hline 24 & 22 & 21.0 & 2.0 & -48 \\
\hline 18 & 8 & 21.0 & 2.0 & -47 \\
\hline 24 & 8 & 21.0 & 2.0 & -56 \\
\hline 36 & 8 & 21.0 & 2.0 & -57 \\
\hline 48 & 8 & 21.0 & 2.0 & -62 \\
\hline
\end{tabular}

${ }^{\mathrm{a}}$ (Grams of dangling chains/grams of polymer precursor $) \times 100$

${ }^{b}$ (Grams of fluorine/total grams of the system) $\times 100$, in the formulation.

microtoming) was used and the cuts were made at a temperature slightly below the $T_{\mathrm{g}}$ of the materials. Since the films had a $T_{\mathrm{g}}$ below RT a Cryostat HM 550 (Microm Systems) was used. The temperature of the sample holder was typically $-35^{\circ} \mathrm{C}$. The slices were rather smooth and contain only a few knife traces. Neither ripping nor nanometer-sized holes were observed. The estimated error of thickness of the slices is about $10 \%$. The newly created surfaces were analyzed with a CA goniometer and XPS to determine the water CA and the F/C atomic ratio, respectively. The self-replenishing efficiency (SRE) was calculated using the equations below:

$$
\begin{aligned}
& \mathrm{SRE}_{\mathrm{F} / \mathrm{C}}=\frac{\mathrm{F} / \mathrm{C}_{\text {afterdamage }}}{\mathrm{F} / \mathrm{C}_{\text {original }}} \times 100(\%), \\
& \mathrm{SRE}_{\mathrm{CA}}=\frac{\mathrm{CA}_{\text {afterdamage }}}{\mathrm{CA}_{\text {original }}} \times 100(\%) .
\end{aligned}
$$

\section{Simulations}

For simulations a coarse grained technique, DPD, was used. The original DPD simulation method was proposed by Hoogerbrugge et al. ${ }^{29}$ while the fluctuation-dissipation theorem for the method was introduced by Groot et al. ${ }^{30}$ Finally, Pagonabarraga et $\mathrm{al}^{31}{ }^{31}$ has introduced a density dependent conservative force into the algorithm. For simulations we have used the PUMMA package ${ }^{32}$ developed at Eindhoven University of Technology by A. J. Markvoort, P. Spijker, and P. Hilbers.

As in a traditional DPD method, each bead represents the volume of several molecules or parts of molecules. DPD describes the temporal evolution of the system via the integration of Newton's equations of motion, $m_{i}\left(\mathrm{~d} \vec{v}_{i} / \mathrm{d} t\right)=\vec{f}_{i}$, where $m_{i}$ and $\vec{v}_{i}$ are the dimensionless mass and velocity of a bead $i$ and $\vec{f}_{i}$ is the total force applied to the bead. For integration, a modified velocity-Verlet algorithm was used. The pairwise additive force acting between non-bonded beads consists of three parts. First, the conservative force, which 
is a soft repulsive force given by $\vec{F}_{i j}^{C}=a_{i j}\left(1-r_{i j} / r_{o}\right) \hat{\vec{r}}_{i j}$, where $a_{i j}$ is a maximum repulsion between beads $i$ and $j$, $\hat{\vec{r}}_{i j}$ is a unit vector, and $r_{0}$ is the characteristic length scale. Second, the random force is $\vec{F}_{i j}^{R}=\sigma \omega_{R}\left(r_{i j}\right) \xi_{i j} \hat{\vec{r}}_{i j}$. Here $\xi_{i j}$ is a zero mean Gaussian random variable of unit variance, $\sigma^{2}=2 k_{B} T \gamma$, where $k_{\mathrm{B}}$ is Boltzmann's constant, $T$ the absolute temperature, and $\gamma$ a viscosity related parameter, while $\omega_{R}$ is a weight function. Third, the dissipative force given by $\vec{F}_{i j}^{D}=-\gamma \omega_{D}\left(r_{i j}\right)\left(\hat{\vec{r}}_{i j} \cdot \vec{v}_{i j}\right) \hat{\vec{r}}_{i j}$, where $\omega_{D}$ is another weight function which goes to zero at $r_{i j}=r_{0}$ and $\vec{v}_{i j}=\vec{v}_{i}-\vec{v}_{j}$. The weight functions $\omega_{R}$ and $\omega_{D}$ for the random and dissipative forces are related via $\omega_{D}\left(r_{i j}\right)=\omega_{R}\left(r_{i j}\right)^{2}$. A characteristic time scale of the model used is defined as $\tau=\left(m r_{0}^{2} / k_{\mathrm{B}} T\right)^{1 / 2}$. The total dimensionless bead number density is $\rho=3$.

\section{Simulation set-ups}

All simulations were performed using periodical boundary conditions. In the beginning of the simulation all the components: polymer precursor, fluorinated dangling chains, cross-linker and one-bead solvent (according to the structures shown in Scheme 1), were placed randomly in the $3 D$ simulation box. In all the systems, $70 \%$ of the simulation box was occupied by the polymer molecules.

\section{Cross-linking}

The original DPD method was modified by introducing the possibility of having permanent cross-links between DPD beads. The cross-links were established when two reactive groups approach each other at a distance smaller than a threshold, which was chosen to be $\Delta d=0.4 r_{\mathrm{eq}}$ where $r_{\mathrm{eq}}$ is the equilibrium distance between the two bonded beads. The amount of cross-linker molecules was calculated to obtain a total ratio of 1.1 between the cross-linker and the total (polymer and dangling chain) reactive beads present in the system. This means that $[3 \times$ (number of cross-linker molecules) $/ 3$ $\times$ (number of polymer molecules) $+1 \times$ (number of dangling chains) $]=1.1$ (see Scheme 1 for details of the chemical structures).

\section{Air/polymer interface set-up}

In this setup part of the simulation box is occupied by the components of the polymer film while the other is occupied by the "void" component (modelled by one bead only) mimicking air. The "void" component is placed on the top of polymer film with the energetic parameters insuring that "void" beads do not penetrate into the polymer film.

\section{Damaging procedure}

For this procedure, a plane is drawn perpendicular to z-direction of the $3 D$ simulation box. All the molecules with center of mass above the damage plane were removed and replaced by air-beads. To avoid artificial swelling of the polymer film after damage, we imposed the condition that the air-beads were not selective to the polymer beads.

\section{Calculation of fluorine profiles and F/C ratio}

The profile of the fluorinated or F-beads was calculated after the simulation systems were equilibrated. The fluorine profile was determined as the number density of F-beads per layer perpendicular to the z-axis of simulation box. To obtain this density, the number of F-beads was integrated over the (lateral) $\mathrm{x}$-y direction of the cell and in the depth over a small bin size $\Delta z$, taken as 0.5 DPD unit (in Figure 1 this profile is represented by every second point). Although the F-bead profile of the simulations and the $\mathrm{F} / \mathrm{C}$ ratio are connected, the relation between these characteristics is not simple because the F-beads (Scheme 1) contain carbon atoms as well as fluorine atoms while their distribution in a bead is inhomogeneous. Hence, in order to calculate the $\mathrm{F} / \mathrm{C}$ ratios for the simulations, we back-mapped the coarse grained model using the procedure of Harmadaris et al. ${ }^{33}$ to an atomistic all-atom representation. Thereafter, employing the Molecular Dynamics package LAMPPS with the COMPASS force field, the structure was equilibrated for $500 \mathrm{ps}$ and the $\mathrm{F} / \mathrm{C}$ ratios calculated.

\section{RESULTS AND DISCUSSION}

Several polymer films were prepared according to methods previously described. ${ }^{26,27}$ Well-defined polycaprolactone-based oligomer precursors with different degree
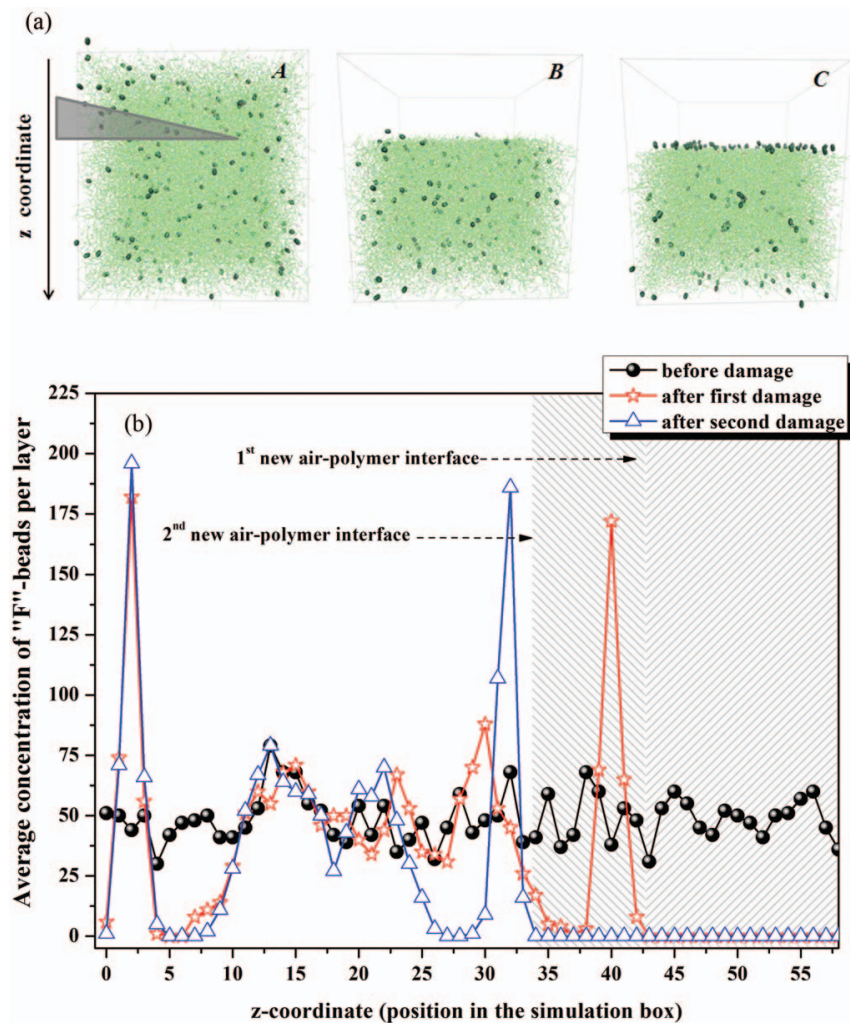

FIG. 1. Simulation of top layer-damages and multiple self-replenishing of films prepared from TMP-PCL 24 and 2 wt. $\%$ of fluorine (via $\mathrm{F}_{17} \mathrm{C}_{8}-\mathrm{PCL}_{16}$ dangling chains): (a) Simulation snapshots of: A - bulk polymer film before damage, $\mathrm{B}$ - polymer film immediately after damage and $\mathrm{C}$-damaged polymer film after equilibration; (b) fluorinated-beads profile as function of $\mathrm{z}$ coordinate (spheres - before the damage and open stars, triangles - after subsequent damages and self-replenishing (i.e., after equilibration) (1 DPD unit $\sim 0.72 \mathrm{~nm})$. 
of polymerization (DP) were used to build the cross-linked bulk network (Scheme $1\left(l_{E X P}\right)$, TMP-PCl ${ }_{\mathrm{x}}$ in Table SM-1). The low surface-energy polymeric dangling chains consisted of perfluoroalkyl-end capped linear polyesters with controlled functionality and DP (Scheme $1\left(2_{E X P}\right)$ and $\mathrm{F}_{17} \mathrm{C}_{8} \mathrm{P}-\mathrm{CL}_{\mathrm{y}}$ in Table SM-2). The low surface energy poly(ester urethane) films were prepared via reaction of the polyester precursors (TMP-PCL $\left.{ }_{\mathrm{x}}\right)$ with the tri-isocyanate (Scheme $1\left(3_{E X P}\right)$ and Table I), using fixed cross-linking conditions such as temperature, solvents and curing time (see experimental for details). Different cross-linked films were prepared from precursors with various DP and a range of fluorine concentrations in the formulation via adjusting the dangling chains concentration (see Table I).

In the DPD simulation study all the experimental components were modelled in a coarse grained manner (Scheme $1_{\text {SIM }}$ ). For the polymer precursor $\left(\mathrm{TMP}-\mathrm{PCL}_{\mathrm{x}}\right.$ ), the caprolactone (CL) repeating units and the TMP initiating group were represented by CL and TMP beads, respectively (Scheme 1). The end-caprolactone reactive units were represented by $\mathrm{C}-\mathrm{H}$-beads. The fluorinated precursors were also modelled with CL-beads for the polymeric spacer and using two F-beads for the fluorinated part (Scheme 1 $\left.\left(2_{S I M}\right)\right)$. The cross-linker was represented by 4 beads (CR and B type) in correspondence with equal volume considerations (Scheme $1\left(3_{S I M}\right)$ ). Solvent and air components were represented by one single bead.

The simulation box was build-up as a 3D cube with periodic boundary conditions. The polymer TMP-PCL $\mathrm{P}_{\mathrm{x}}$, the fluorinated dangling chains $\mathrm{F}_{17} \mathrm{C}_{8}-\mathrm{PCL}_{\mathrm{y}}$, the cross-linker, and the solvent were placed randomly in the box, ${ }^{30,34}$ keeping the overall reduced density, $\rho=3$. The air-polymer interface was modelled by placing a layer of air-beads at the top of the polymer film. A typical system contained an excess of crosslinker (total number of cross-linker reactive beads (CR)/total number of polymers reactive beads $(\mathrm{C}-\mathrm{H})=1.1)$ and, after sufficient time of equilibration, $\sim 99 \%$ of cross-linking was typically reached. The profiles of the F-beads were calculated to characterize the distribution of fluorine throughout the polymer film. The number of F-beads was calculated per layer and integrated in x-y direction. Figure 1(b) shows typical fluorine profiles as a function of the $\mathrm{z}$ coordinate (i.e., the position in the simulation box) which represents the polymer film thickness (1 DPD unit $\sim 0.72 \mathrm{~nm}$ ).

\section{A. Intentional damage inflicted on the polymeric films}

To evaluate the self-replenishing ability, intentional damages were inflicted in the cross-linked films. In the experimental approach, the films were damaged using a microtome to remove layers of the films, in steps of a few tens of micrometers, in a direction parallel to the air-polymer interface, up to a depth of $60 \mu \mathrm{m}$ through the bulk of the film (initial film thickness $\sim 500 \mu \mathrm{m}$ ). To avoid introducing artefacts at the surface such as large roughness, knife profiles or smeared material, which may affect the characterization after damage, the films were microtomed using a special holder set-up described previously ${ }^{26}$ and at cryo-conditions $\left(-35^{\circ} \mathrm{C}\right.$, close to the $T_{g}$ of the polymer films, see Table I). The original films ( $0 \mu \mathrm{m}$ depth), the slices, and the final damaged film (at $60 \mu \mathrm{m}$ depth) were characterized by XPS and water CA measurements.

For the simulations of the self-replenishing we have chosen to start with the "bulk" material configuration (see methods description). This choice was based on the fact that in the experimental approach, a typical damage is in the order of tens of micrometers. Thus, any cut/damage will go through the "bulk" material where the structure of the polymer network and the distribution of dangling chains will not be affected by the initial air-polymer interface.

After the polymer film was sufficiently equilibrated and cross-linked, the film damage was modeled by removing approximately $15 \mathrm{~nm}$ of the simulation box in a plane perpendicular to the z-coordinate (Figure 1(a)(A)). Next, the polymer beads removed were replaced by air-beads, mimicking a new air layer Figure 1(a)(B) and the system was equilibrated Figure 1(a)(C). To avoid artificial swelling of the polymer film after the damage procedure, we have imposed the condition that the air-beads were not selective to the polymer beads. For the details of the parameterization, see the supplementary material. ${ }^{43}$

\section{B. Self-replenishing and multiple healing events}

Immediately after the damaging procedure described above is applied to the simulation box, the dangling chains are homogeneously distributed throughout the cross-linked film (Figure 1(a)(B)). After sufficient time of equilibration, the dangling chains of the top-layer exposed by the damage to a new air layer re-orient towards the new air-polymer interface (Figure 1(a)(C)). The surface segregation of fluorine can also be clearly seen by the F-beads profiles (Figure 1(b), stars).

Interestingly, a new depletion zone is formed just beneath the new F-beads enriched surface layer. As the starting system before damage is a fully cross-linked polymer film ( $\sim 99 \%)$, only the dangling chains at the region below the damage plane can re-orient towards the new "damage-created" air-polymer interface. Hence, the thickness of the region from which the F-beads can re-orient corresponds to the thickness of the depletion layer which was estimated to be $\sim 5 \mathrm{~nm}$. The presence of a depletion zone was already reported in our first study of the surface self-segregation which occurs during film formation. ${ }^{27}$ From the F-beads profiles in Figure 1(b), it is also possible to observe that after damage the F-beads concentration remains at the average bulk value of the un-damaged film. This allows multiple healing events throughout the film by inflicting repeated damaging procedures (i.e., cutting at different depths of the simulation box) and allowing the system to recover. Moreover, the F-beads profiles of two subsequent cuts (Figure 1(b), stars and triangles) show that the level of the surface segregation after the second damage is close to the value before damage, indicating that the functionality of the film can be nearly completely recovered.

In a parallel experimental approach, cross-linked films prepared with parameters equivalent to the simulation study (i.e., the same polymer precursors TMP- $\mathrm{PCL}_{24}$ and an initial concentration of fluorine of 2 wt. $\%$ ) were intentionally 
damaged, by microtoming slices at different depths of the fully cross-linked polymer films, which were then allowed to recover at room temperature. In Figure 2 two examples of cross-linked films prepared with dangling chains with different DP (8 and 24) are shown. The reason why we observe such high F/C ratios by the XPS measurements has to do with the fact that we probe several "layers" of the cross-linked network. These "layers" contain a high concentration of perfluorinated tails of the dangling chains, due to their preference for the interface. Note that the cross-linked films have a significant number of dangling chains in relation to the total number of chains, up to $21 \%$, and that the number of $\mathrm{CL}$ units in-between cross-links is about 8, (i.e., length roughly $8 \mathrm{~nm})$ while the number of CL units in the polymeric spacer of the dangling chains is much larger, up to $16(\sim 16 \mathrm{~nm})$. Hence, due to the preference of the perfluorinated tails for the air interface, the dangling chains from deeper "layers" with their large range contribute to the presence of perfluorinated tails in the "network layers" probed by XPS. Similar results on functional polymer systems have been reported by other authors, as reviewed by Koberstein. ${ }^{35}$ It has been shown through XPS ${ }^{36}$ and also theoretical models ${ }^{37}$ that, in the case low surface energy functional groups, the first "layer" (at the air-interface) contains the highest concentration of functional groups, and that a depletion of functional groups exists at the second "layer." For similar cross-linked polymer films containing dangling chains, a strong enrichment of the outermost surfaces with low surface energy components has also been reported and demonstrated using XPS by van Grampel et al. ${ }^{38}$

From Figure 2, it can be seen that the F/C atomic ratios after damage (determined from XPS at a probe depth of $\sim 10 \mathrm{~nm}$ ) remain fairly constant all through the depth of the films (up to $60 \mu \mathrm{m}$ deep) (Figure 2, closed symbols). This is clear experimental evidence of the ability of the cross-linked

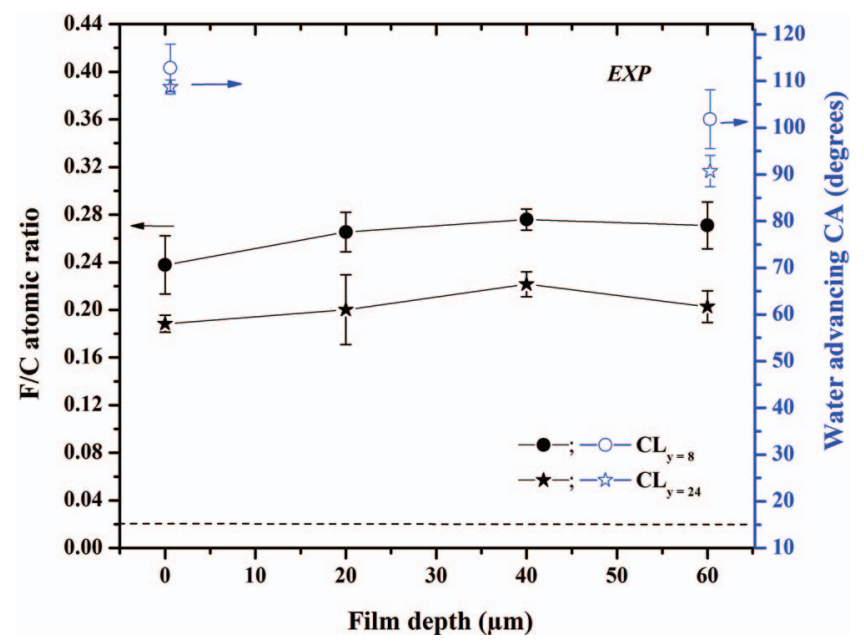

FIG. 2. Experimental results showing the multiple self-replenishing on films at different film depths: (left) F/C ratio (calculated from XPS averaged from a probe depth of $\sim 10 \mathrm{~nm}$ ) measured on slices microtomed from the first air-polymer interface, on a horizontal plane parallel direction (closed symbols). Values at " $0 \mu \mathrm{m}$ " represent the original surface before microtoming; (right) advancing water Contact Angle (CA) measured after a total of $60 \mu \mathrm{m}$ layer has been microtomed (open symbols). TMP-PCL 24 network precursor, $\mathrm{F}_{17} \mathrm{C}_{8}-\mathrm{PCL}_{\mathrm{y}}, \mathrm{y}=8,24$ dangling chains and $2 \mathrm{wt} . \%$ of fluorine were used in the formulation. films to self-replenish the surface composition over multiple damages inflicted throughout the bulk. It should also be noticed that the F/C atomic ratio obtained before and after the damaging events is largely above the theoretical value expected for the "bulk," assuming that the $2 \mathrm{wt} . \%$ of fluorine used would be homogeneously distributed throughout the film (dashed line in Figure 2). Hence, upon damage and recreation of new air-interfaces, the new "top-network layers" become self-replenished by the re-orientation of the dangling chains from the just-beneath layers.

The macroscopic wettability of the films was also investigated by measuring the dynamic water contact angles before and after damage. In the same Figure 2 (open symbols) it can be seen that, for both cross-linked films, the advancing water CA is not completely recovered. It should be noticed, however, that the surface wettability after damage remains in the hydrophobic region, even after multiple damages have been inflicted throughout the cross-linked film. This somewhat lower recovery of the surface wettability may be due to the introduction of surface artifacts inherent to the damaging procedure or to surface reorientation aspects, as discussed in detail later in this paper.

Both experimental and simulation results coherently show the ability of the cross-linked films for multiple selfreplenishing of the surface composition. Moreover, from the simulation results it can be inferred that the direction of damage does not play a role because in the "bulk" material, which serves as initial configuration before damage, there is no preferential direction. That means that if the damage occurs in any other direction of the simulation box the recovery of the low surface energy groups will have the same effectiveness. Hence, it can also be expected that if damage on an experimentally prepared film occurs in a different direction than parallel to the air-polymer interface (i.e., propagation of a crack in a different directions into the bulk), it should be equally able to self-replenish.

\section{Self-replenishing efficiency and minimum "healing agent" concentration}

Other important aspects concerning the self-replenishing ability of these polymer films are: 1) how the concentration of fluorine content in the formulation (i.e., "healing agent" availability) affects the surface recovery and 2) finding a fluorine concentration threshold for the self-replenishing. To address these points, cross-linked polymer films were modeled with TMP-PCL 24 network precursors, $\mathrm{F}_{17} \mathrm{C}_{8}-\mathrm{PCL}_{16}$ dangling chains and a fluorine content varying from 0.5 to $3.0 \mathrm{wt} . \%$. The damaging procedure was applied equally to all the films, which were then equilibrated and allowed to replenish. Figure 3 shows simulation results for the F/C ratios calculated for the original surface and after one damage event and equilibration.

From Figure 1 it is clear that the F-bead ratio of surface and bulk is about four, while the experimentally determined F/C ratio by XPS is about twelve (see Figure 2). As stated before, the relation between these characteristics is not simple because the F-beads (Scheme 1) contain carbon atoms as well as fluorine atoms while their distribution in a bead is 


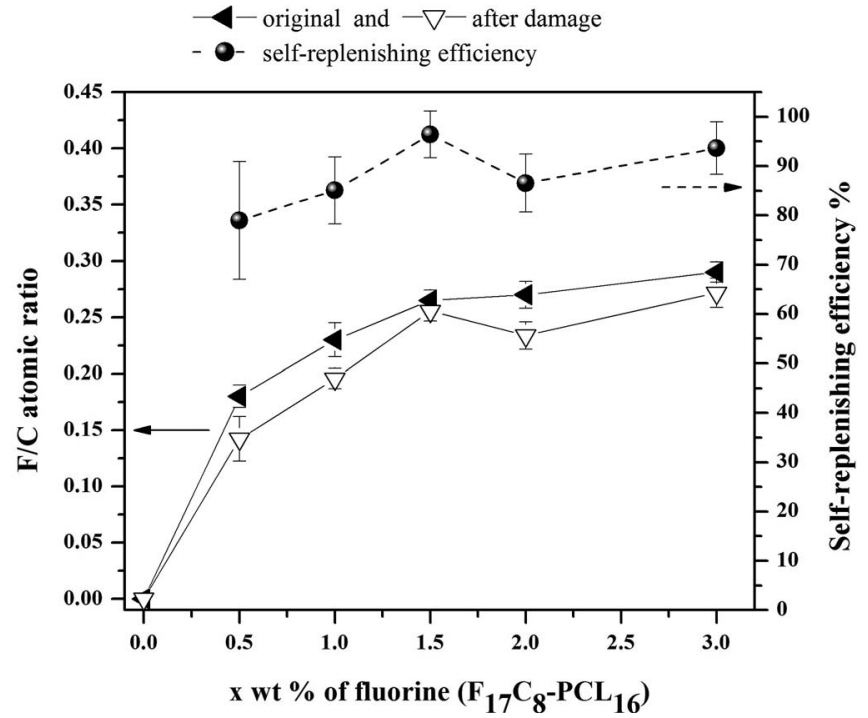

FIG. 3. Simulation results showing: (left) the F/C atomic ratio before ( 4 ) and after $(\Delta)$ damage and equilibration of the polymer films and (right) selfreplenishing efficiency versus different concentrations of fluorine in the formulation (\% wt of F). TMP- $\mathrm{PCL}_{24}$ network precursor and $\mathrm{F}_{17} \mathrm{C}_{8}-\mathrm{PCL}_{16}$ dangling chains were used.

inhomogeneous. That is why the back-mapping to an allatomistic model was done from which, after equilibration, the $\mathrm{F} / \mathrm{C}$ ratio was determined, as given in Figure 3. Note that the values for the $\mathrm{F} / \mathrm{C}$ ratio in Figure 3 are integrated values over the exponentially decaying response with probing depth (reduction of intensity to $1 / e$ ) of about $10 \mathrm{~nm}$. The estimated ratio of the surface $\mathrm{F} / \mathrm{C}$ value $(0.25)$ over bulk $\mathrm{F} / \mathrm{C}$ value $(0.02)$ is thus also about 12 and therefore compares favorably with the XPS results.

Using the $\mathrm{F} / \mathrm{C}$ values and Eq. (2), the self-replenishing efficiency (SRE) can be estimated (see Figure 3). From the simulation results, all the cross-linked films recover well above $80 \%$ of their original surface segregation values. As the fluorine concentration increases, a maximum of $\sim 96 \%$ recovery is reached for a concentration of $1.5 \mathrm{wt} \%$ of fluorine. In our previous work ${ }^{27}$ on the surface self-segregation upon film formation, we reported that although the water advancing $\mathrm{CA}$ reaches a plateau $\left(\mathrm{CA}=114^{\circ} \pm 2^{\circ}\right)$ at about $1.5-2 \mathrm{wt} \%$ of fluorine, the $\mathrm{F} / \mathrm{C}$ ratio indicated that the fluorine concentration at the surface increased continuously with increasing concentration of fluorine in the formulation (obtained with good agreement between experiments and simulations). The current results indicate that a similar fluorine concentration in the formulation is equally critical for obtaining the maximum of surface recovery, i.e., the minimum "healing agent" concentration in the formulation for obtaining a maximum recovery of surface hydrophobicity would be for these systems, around $1.5 \mathrm{wt} . \%$ of the low surface energy component.

\section{Molecular mobility span of the dangling chains}

To investigate the influence of the molecular mobility span of the dangling chains, cross-linked films were prepared with the TMP-PCL 24 network precursor and $\mathrm{F}_{17} \mathrm{C}_{8}-\mathrm{PCL}_{\mathrm{y}}$ dangling chains with a DP varying from 8 to 24 and a constant
2 wt.\% of $\mathrm{F}$ in the formulation. All the films were damaged in the same conditions, following the procedures described above for the experimental and simulations approaches. In Figures 4(a) and 4(b), the $\mathrm{F} / \mathrm{C}$ atomic ratios are shown for the original systems and also after the damage and selfreplenishing took place. For the experimental study, a total of $60 \mu \mathrm{m}$ layer was removed by microtoming and the films were allowed to recover at room temperature. For the simulations, $\sim 15 \mathrm{~nm}$ was removed from the original bulk simulation box and sufficient time for equilibration was allowed. From these data the self-replenishing efficiency can be calculated according to Eq. (2), and the results obtained are shown in Table II.

In both approaches, the films show an enrichment of the surface with fluorine species (i.e., above the theoretical value of 0.02) after damage. From the simulation results no particular trend is observed for the variation of the length of the polymeric spacer: all films recover up to $75 \%-80 \%$ of their initial F/C value. In the experimental approach, a full replenishment of the F/C atomic ratio is observed for the damaged films; however, the ultimate self-replenishing ability should be evaluated by the capability of the films to recover their initial wettability. The water advancing CA measured on films before and after damage, as a function of the length (DP) of the dangling chains, are shown in Figure 5(a). The respective self-replenishing efficiency (SRE) can be calculated using these values and Eq. (3), see Table II. In this case all the films were able to recover up to $90 \%$ of their original wettability. Although no particular trend could be observed, the films with shorter polymeric spacers seem to perform slightly better.

One of the difficulties of evaluating in practice the selfreplenishing ability is finding a procedure to damage the polymer films in such a way that the characterization after

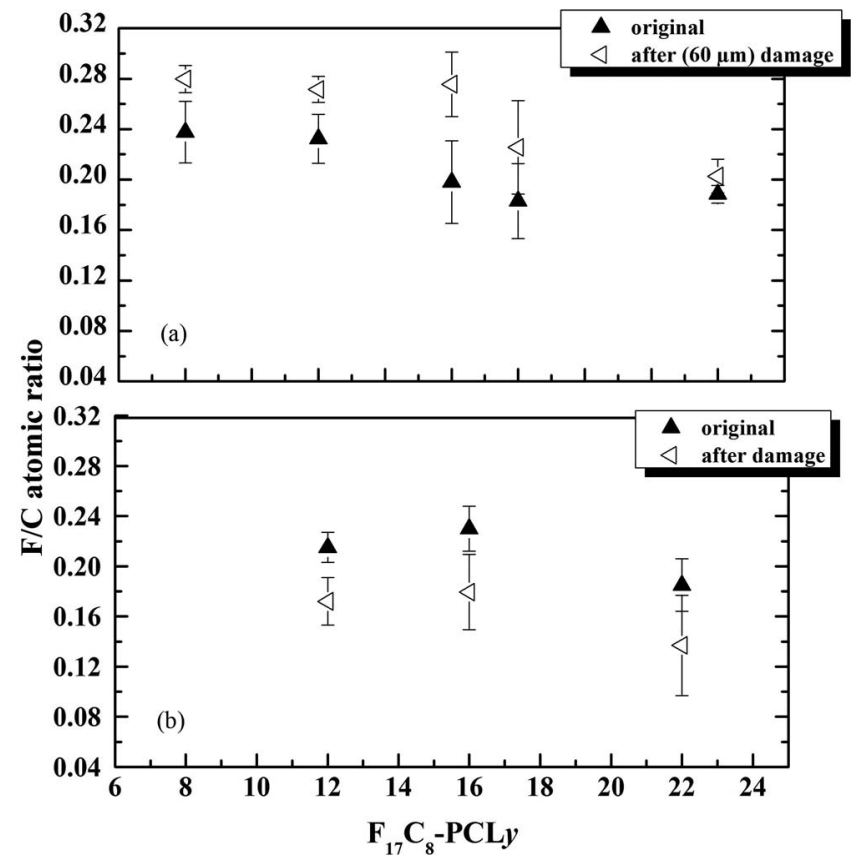

FIG. 4. Fluorine/carbon (F/C) atomic ratio as a function of the length (DP) of the dangling chains $\left(\mathrm{F}_{17} \mathrm{C}_{8} \mathrm{PCL}_{\mathrm{y}}, y=\right.$ total $\mathrm{CL}$ units) using TMP-PCL 24 network precursor and $2 \mathrm{wt} . \%$ of fluorine in the formulation: (a) experimental and (b) simulation. The error bars indicate the sample standard deviation. 
TABLE II. Self-replenishing efficiency (SRE, \%) based on water advancing CA and F/C atomic ratio measurements (experimental) or calculations (simulation), before and after damage. The numbers in italic and bold denote different sets of films.

\begin{tabular}{|c|c|c|c|c|}
\hline $\begin{array}{l}\text { TMP-PCL }_{x} \\
x=\end{array}$ & $\begin{array}{c}\mathrm{F}_{17} \mathrm{C}_{8}-\mathrm{PCL}_{\mathrm{y}} \\
\mathrm{y}=\end{array}$ & $\begin{array}{l}\mathrm{SRE}(\%) \text { based on } \\
\mathrm{F} / \mathrm{C} \text { atomic ratio }{ }^{\mathrm{a}}- \\
\quad \text { experimental }\end{array}$ & $\begin{array}{l}\mathrm{SRE}(\%) \text { based on } \\
\mathrm{F} / \mathrm{C} \text { atomic ratio }{ }^{\mathrm{a}}- \\
\text { simulation }\end{array}$ & $\begin{array}{c}\text { SRE }(\%) \text { based } \\
\text { on } \mathrm{CA}^{\mathrm{b}}- \\
\text { experimental }\end{array}$ \\
\hline 24 & 8 & $118 \pm 13$ & $\ldots$ & $90 \pm 7$ \\
\hline 24 & 12 & $117 \pm 11$ & $80 \pm 10$ & $80 \pm 3$ \\
\hline 24 & 16 & $139 \pm 26$ & $78 \pm 14$ & $84 \pm 3$ \\
\hline 24 & 18 & $123 \pm 28$ & $\ldots$ & $86 \pm 3$ \\
\hline 24 & 22 & $\ldots$ & $74 \pm 23$ & $\ldots$ \\
\hline 24 & 24 & $123 \pm 8$ & $\ldots$ & $83 \pm 3$ \\
\hline 18 & 16 & $116 \pm 9$ & $80 \pm 11$ & $92 \pm 2$ \\
\hline 24 & 16 & $139 \pm 26$ & $85 \pm 11$ & $84 \pm 3$ \\
\hline 36 & 16 & $163 \pm 59$ & $87 \pm 13$ & $83 \pm 4$ \\
\hline 48 & 16 & $\ldots$ & $82 \pm 10$ & $75 \pm 3$ \\
\hline
\end{tabular}

${ }^{\mathrm{a}}$ From data in Figure 4 and Figure SM-1, and using Eq. (2).

${ }^{\mathrm{b}}$ From data in Figure 5 and using Eq. (3).

damage will not be affected by the damage itself. The cryomicrotoming technique used is one of the most reliable ways that we have found to inflict controlled damages without introducing to many artifacts at the surface. ${ }^{39}$ Nevertheless, both the F/C and CA values measured after damage may have
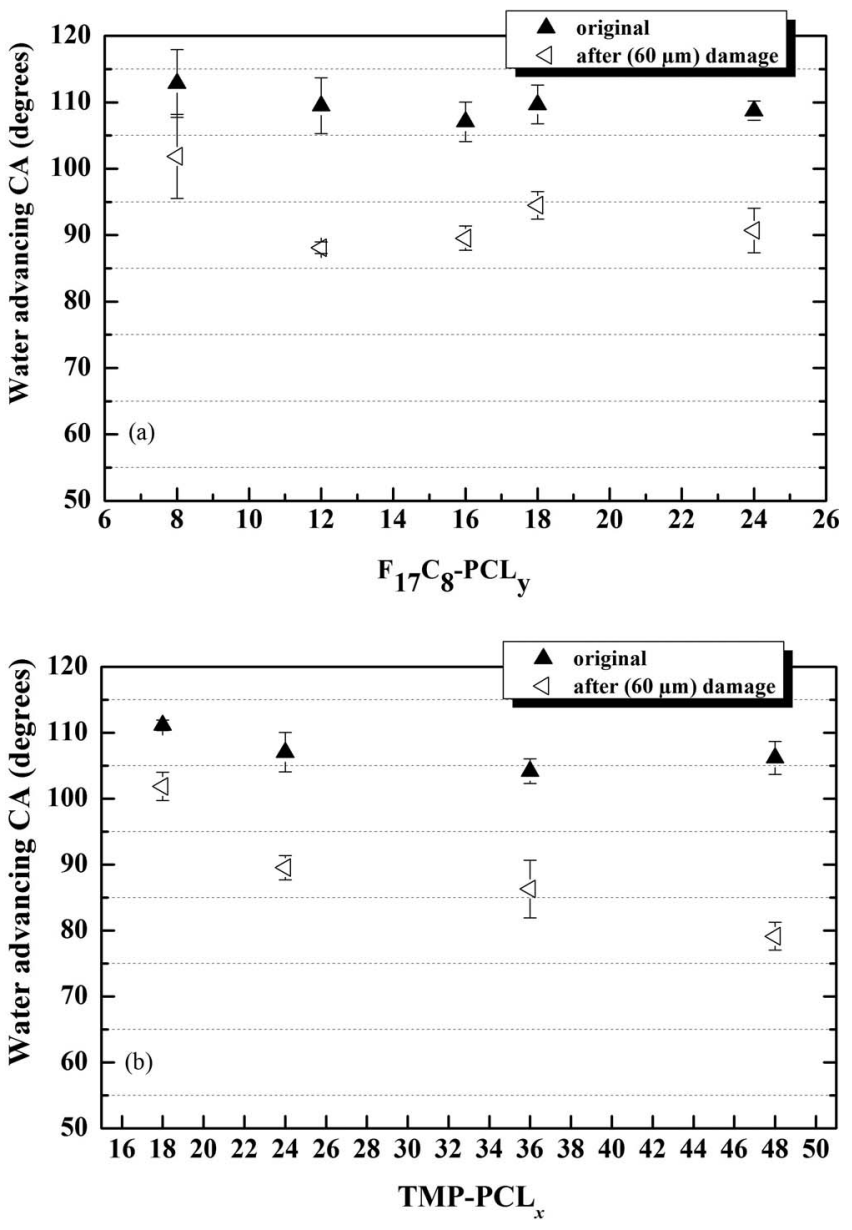

FIG. 5. Experimental: Water advancing water (CA) as a function of: (a) the length (DP) of the dangling chains $\left(\mathrm{F}_{17} \mathrm{C}_{8}-\mathrm{PCL}_{\mathrm{y}}, y=\right.$ total $\mathrm{CL}$ units), with TMP-PCL 24 network precursor and $2 \mathrm{wt} \%$ of fluorine in the formulation and (b) the length (DP) of the polymer network precursor (TMP-PCL $\mathrm{P}_{\mathrm{x}}$ ) with $\mathrm{F}_{17} \mathrm{C}_{8}-\mathrm{PCL}_{16}$ dangling chains and $2 \mathrm{wt} . \%$ of fluorine in the formulation. considerable additional errors since the damaged surfaces are consequently different from the original ones (see error considerations in the supplementary material). ${ }^{43}$

In summary, from the experimental and simulation approaches no particular effect was observed on the selfreplenishing ability of the cross-linked films prepared while using dangling ends with different span mobility. The simulations predict about $70 \%-80 \%$ recovery of the surface composition, and in practice all the films showed recovery ability well above $80 \%$ of the initial water CA. The difference observed between the recovery of the experimental and simulation $\mathrm{F} / \mathrm{C}$ atomic ratio may be related to the balance between the diffusion and surface-segregation of the "healing agents" (i.e., fluorinated dangling chains) and the formation of the cross-linked network, which is severely affected by the filmforming conditions, namely the temperature of curing. ${ }^{38,40,41}$ In fact, simulations run at different cross-linking rates (not shown), which would correspond to using different temperatures of curing, revealed a strong influence of this parameter on the surface-segregation of the dangling chains.

\section{E. Network segment length effects}

Finally, we investigated the influence of the network parameters on the self-replenishing ability of the cross-linked films, namely the length of the polymeric segment between cross-links of the bulk network (as given by the DP of the bulk precursor). For this purpose films containing TMP- $\mathrm{PCL}_{\mathrm{x}}$ precursors with DP varying from 16 to 48 and $2 \mathrm{wt}$.\% of fluorine in the formulation (inserted via $\mathrm{F}_{17} \mathrm{C}_{8}-\mathrm{PCL}_{16}$ dangling chains) were prepared. Similar, experimental and simulation, damaging and self-replenishing procedures as described above were applied to the cross-linked films.

The simulation and experimental results obtained for the $\mathrm{F} / \mathrm{C}$ atomic ratios and self-replenishing efficiency in terms of surface composition recovery are shown in Table II and Figure SM-1. The simulations showed no particular trend with an average recovery of about $85 \%$ for the surface composition, while the experimental results showed a full replenishment of the surface (see the supplementary material). ${ }^{43}$ 
The results on the recovery of the surface wettability are, however, significantly different (see Figure 5(b) and Table II). The self-replenishing ability decreases with increasing length of the polymeric segments in-between cross-links of the bulk network from $\sim 92$ down to $75 \%$. The caprolactone based systems, as used in this study, have been reported to have large $\mathrm{CA}$ hysteresis due to surface-rearrangements ${ }^{27}$ or permanent damages on the network by extensive contact with water, e.g., by hydrolyses of the ester bonds. These aspects could be playing an important role here, since the final CA for the films made with the longest polymeric segment $(\mathrm{DP}=48)$, reaches values below $90^{\circ}$ (i.e., hydrophilic) (Figure 5(b)).

\section{CONCLUSIONS}

The self-replenishing ability of low surface energy crosslinked poly(ester urethane) films containing perfluorinated dangling chains was evaluated by a dual experimentalsimulation approach. The combined study revealed that these systems are able to go through multiple-healing events up to a depth of $60 \mu \mathrm{m}$ in a fully cross-linked film, and that the surface replenishment occurs by the re-orientation of the dangling ends at the top $5 \mathrm{~nm}$ of the new surfaces created upon damage. Furthermore, the minimum "healing agent" concentration in the formulation to achieve a maximum of recovery of the surface composition (around 90\%) was determined to be about $1.5 \mathrm{wt} . \%$ of fluorine in relation to the bulk polymer.

The molecular span mobility of the dangling chains did not seem to significantly affect the surface composition recovery neither the self-replenishing efficiency (SRE) in terms of surface wettability (on average SRE 85\%). On the other hand, the properties of the network precursors, i.e., the polymeric segments between cross-links, seem to have a clear effect on the wettability recovery as the SRE decreases significantly with the length of the polymeric segment on the bulk network.

The current work shows that in spite of using different system parameters, the cross-linked polymeric films studied exhibit a quite efficient self-replenishing ability. It also provides clear guidelines for choosing the best parameters for the creation of effective self-healing systems. Hence, the self-replenishing principle studied here in detail consists of a rather universal and effective autonomous and intrinsic selfhealing mechanism to recover surface properties and increase the life-time of surface functional materials. The extension of this efficient self-healing principle to complex systems, including structured surfaces on inorganic-organic composite materials will be reported in Ref. 42.

\section{ACKNOWLEDGMENTS}

The authors thank the Dutch Ministry of Economic Affairs, Agriculture and Innovation via the IOP-Self-Healing materials program (Project No. SHM08710). The authors thank Dr. A. J. Markvoort for useful discussions.

${ }^{1}$ I. P. Parkin and R. G. Palgrave, J. Mater. Chem. 15, 1689 (2005).

${ }^{2}$ M. B. Yagci, S. Bolca, J. P. A. Heuts, W. Ming, and G. de With, Prog. Org. Coat. 72, 305 (2011).

${ }^{3}$ I. Banerjee, R. C. Pangule, and R. S. Kane, Adv. Mater. 23, 690 (2011).
${ }^{4}$ S. van der Zwaag, Self-Healing Materials: An Alternative Approach to 20 Centuries of Materials Science (Springer, Dordrecht, The Netherlands, 2007), Vol. 100.

${ }^{5}$ R. P. Wool, Soft Matter 4, 400 (2008).

${ }^{6}$ D. Y. Wu, S. Meure, and D. Solomon, Prog. Polym. Sci. 33, 479 (2008)

${ }^{7}$ Y. Yang and M. W. Urban, Chem. Soc. Rev. 42, 7446 (2013).

${ }^{8}$ E. B. Murphy and F. Wudl, Prog. Polym. Sci. 35, 223 (2010).

${ }^{9}$ S. D. Bergman and F. Wudl, J. Mater. Chem. 18, 41 (2008).

${ }^{10}$ M. W. Urban, Prog. Polym. Sci. 34, 679 (2009).

${ }^{11}$ J. A. Syrett, C. R. Becer, and D. M. Haddleton, Polym. Chem. 1, 978 (2010).

${ }^{12}$ S. J. García, H. R. Fischer, and S. van der Zwaag, Prog. Org. Coat. 72, 211 (2011).

${ }^{13}$ M. Samadzadeh, S. H. Boura, M. Peikari, S. M. Kasiriha, and A. Ashrafi, Prog. Org. Coat. 68, 159 (2010).

${ }^{14}$ S. H. Cho, S. R. White, and P. V. Braun, Adv. Mater. 21, 645 (2009).

${ }^{15}$ J. L. Wietor, A. Dimopoulos, L. E. Govaert, R. A. T. M. van Benthem, G. de With, and R. P. Sijbesma, Macromolecules 42, 6640 (2009).

${ }^{16} \mathrm{~F}$. Tournilhac, P. Cordier, D. Montarnal, C. Soulie-Ziakovic, and L. Leibler, Macromolecular Symposia 291-292, 84 (2010).

${ }^{17}$ P. Cordier, F. Tournilhac, C. Soulie-Ziakovic, and L. Leibler, Nature (London) 451, 977 (2008).

${ }^{18}$ J. Canadell, H. Goossens, and B. Klumperman, Macromolecules 44, 2536 (2011).

${ }^{19}$ M. Pepels, I. Filot, B. Klumperman, and H. Goossens, Polym. Chem. 4, 4955 (2013).

${ }^{20}$ J. L. Yang, M. W. Keller, J. S. Moore, S. R. White, and N. R. Sottos, Macromolecules 41, 9650 (2008).

${ }^{21}$ M. X. Huang and J. L. Yang, J. Mater. Chem. 21, 11123 (2011).

${ }^{22}$ A. C. Jackson, J. A. Bartelt, K. Marczewski, N. R. Sottos, and P. V. Braun, Macromol. Rapid Commun. 32, 82 (2011).

${ }^{23}$ B. J. Blaiszik, M. M. Caruso, D. A. McIlroy, J. S. Moore, S. R. White, and N. R. Sottos, Polymer 50, 990 (2009).

${ }^{24}$ K. S. Toohey, N. R. Sottos, J. A. Lewis, J. S. Moore, and S. R. White, Nat. Mater. 6, 581 (2007).

${ }^{25}$ A. R. Hamilton, N. R. Sottos, and S. R. White, Adv. Mater. 22, 5159 (2010).

${ }^{26}$ T. Dikic, W. Ming, R. A. T. M. van Benthem, A. C. C. Esteves, and G. de With, Adv. Mater. 24, 3701 (2012).

${ }^{27}$ A. C. C. Esteves, K. Lyakhova, L. G. J. van der Ven, R. A. T. M. van Benthem, and G. de With, Macromolecules 46, 1993 (2013).

${ }^{28}$ T. Dikić, W. Ming, P. Thüne, R. Van Benthem, and G. de With, J. Polym. Sci. A 46, 218 (2008).

${ }^{29}$ P. J. Hoogerbrugge and J. M. V. A. Koelman, Europhys. Lett. 19, 155 (1992).

${ }^{30}$ R. D. Groot and P. B. Warren, J. Chem. Phys. 107, 4423 (1997).

${ }^{31}$ I. Pagonabarraga and D. Frenkel, J. Chem. Phys. 115, 5015 (2001).

${ }^{32}$ For information on the Molecular Dynamics Code PumMa (Parallel Utility for Modeling of Molecular Aggregation), focusing on coarsegrained models and developed at Eindhoven University of Technology, see www.pumma.nl.

${ }^{33}$ V. A. Harmandaris, N. P. Adhikari, N. F. A. van der Vegt, and K. Kremer, Macromolecules 39, 6708 (2006).

${ }^{34}$ R. D. Groot, J. Chem. Phys. 118, 11265 (2003).

${ }^{35}$ J. T. Koberstein, J. Polym. Sci. Polym. Phys. 42, 2942 (2004).

${ }^{36}$ C. J. Jalbert, J. T. Koberstein, R. Balaji, Q. Bhatia, L. Salvati, and I. Yilgor, Macromolecules 27, 2409 (1994).

${ }^{37}$ C. J. Jalbert, J. T. Koberstein, A. Hariharan, and S. K. Kumar, Macromolecules 30, 4481 (1997).

${ }^{38}$ R. D. van de Grampel, W. Ming, W. J. H. van Gennip, F. van der Velden, J. Laven, J. W. Niemantsverdriet, and R. van der Linde, Polymer 46, 10531 (2005).

${ }^{39}$ S. J. Hinder, J. F. Watts, and C. Lowe, Surf. Interface Anal. 36, 1032 (2004).

${ }^{40}$ W. Ming, M. Tian, R. D. van de Grampel, F. Melis, X. Jia, J. Loos, and R. van der Linde, Macromolecules 35, 6920 (2002).

${ }^{41}$ W. Ming, F. Melis, R. D. van de Grampel, L. van Ravenstein, M. Tian, and R. van der Linde, Prog. Org. Coat. 48, 316 (2003).

${ }^{42}$ K. Lyakhova, A. C. C. Esteves, M. W. P. de Put, L. G. J. van der Ven, R. A. T. M. van Benthem, and G. de With, "Simulation-experimental approach to investigate the role of interfaces in self-replenishing composite coatings," Adv. Mater. Interfaces (in press).

${ }^{43}$ See supplementary material at http://dx.doi.org/10.1063/1.4868989 for simulation methods details, full characterization of the polymer precursors and coating formulations, and errors considerations for F/C and CA experiments. 